Article

\title{
Application of Graphene and Carbon Nanotubes on Carbon Felt Electrodes for the Electro-Fenton System
}

\author{
Yi-Ta Wang ${ }^{1, *}$, Chang-Hung Tu ${ }^{1}$ and Yue-Sheng Lin ${ }^{2}$ \\ 1 Department of Mechanical and Electro-Mechanical Engineering, National I-Lan University, Yilan City 26047, \\ Taiwan; kjh615243henry@gmail.com \\ 2 Department of Mechanical Engineering, National Taiwan University of Science and Technology, \\ Taipei City 10607, Taiwan; b0222086@gmail.com \\ * Correspondence: ytwang@niu.edu.tw; Tel.: +886-3-9357400-7457; Fax: +886-3-9311326
}

Received: 3 April 2019; Accepted: 23 May 2019; Published: 25 May 2019

check for updates

\begin{abstract}
The electro-Fenton system has the ability to degrade wastewater and has received attention from many researchers. Currently, the core development objective is to effectively increase the degraded wastewater decolorization efficiency in the system. In this study, to improve the electro-Fenton system reaction rate and overall electrical properties, we used polyvinylidene difluoride to fix carbon nanotubes (CNTs) and graphene onto the system cathode (carbon felt electrode), which was then used to process Reactive Black 5 wastewater. Furthermore, we (1) used scanning electron microscopy to observe the structural changes in the electrode surface after modification; (2) used the Tafel curve to determine the electrode corrosion voltage and corrosion rate; and (3) analyzed the azo-dye decolorization level. The results showed that the maximum system decolorization rates of the CNT- and graphene-modified carbon felt electrodes were $55.3 \%$ and $70.1 \%$, respectively. These rates were, respectively, 1.2 and 1.5 times higher than that of the unmodified carbon felt electrode, implying that we successfully improved the cathode characteristics. The modified electrode exhibited an improved conductivity and corrosion resistance, which, in turn, improved the system decolorization efficiency. This significantly increased the electro-Fenton system overall efficacy, making it valuable for future applications.
\end{abstract}

Keywords: electro-Fenton system; cathode; graphene; carbon nanotubes; polyvinylidene difluoride

\section{Introduction}

In recent years, industrial dyeing and finishing processes have produced a large amount of wastewater. This wastewater often contains many organic and inorganic pollutants such as pastes, grease, and dye interface activation agents that are difficult for microbes to break down. The electro-Fenton process is one of the advanced oxidation processes (AOPs) for the treatment of wastewater of low to moderate organic strength [1]. When power is supplied, the system reaction commences and electrons $\left(\mathrm{e}^{-}\right)$and hydrogen ions $\left(\mathrm{H}^{+}\right)$are generated; they promote the reduction of the dissolved oxygen $\left(\mathrm{O}_{2}\right)$ in the solution into hydrogen peroxide $\left(\mathrm{H}_{2} \mathrm{O}_{2}\right)$. After ferric ions accept electrons, they are reduced to ferrous ions, which react with the $\mathrm{H}_{2} \mathrm{O}_{2}$ produced by the system. This reaction produces hydroxyl radical $\left(\bullet^{\circ} \mathrm{OH}\right)$ and ferric ions, which are important for degrading wastewater. The reaction of an azo dye with hydroxyl radical can help clean the wastewater [1]. With continuous electrical supply, ferric ions will be reduced once more to ferrous ions, which will continue to react with $\mathrm{H}_{2} \mathrm{O}_{2}$ and produce hydroxyl radicals, forming the electro-Fenton system cycle. The respective chemical reactions (Equations (1)-(3)) are given below [2,3].

$$
2 \mathrm{H}^{+}+2 \mathrm{e}^{-}+\mathrm{O}_{2} \rightarrow \mathrm{H}_{2} \mathrm{O}_{2}
$$




$$
\begin{gathered}
\mathrm{Fe}^{3+}+\mathrm{e}^{-} \rightarrow \mathrm{Fe}^{2+}, \\
\mathrm{Fe}^{2+}+\mathrm{H}_{2} \mathrm{O}_{2}+\mathrm{H}^{+} \rightarrow \mathrm{Fe}^{3+}+\mathrm{H}_{2} \mathrm{O}+{ }^{\bullet} \mathrm{OH} .
\end{gathered}
$$

The characteristics of the electrode are the main factors that affect the system reaction efficiency. Selection of the cathode electrode is mainly based on good conductivity, good corrosion resistance, high specific surface area, and high stability [4]. More recently, advances have been made using carbon materials due to their non-toxicity, high specific surface area, good electrical conductivity, and high chemical stability. A variety of conductive carbon materials have been successfully used in the electro-Fenton system [5]. Ganiyu et al. found that CoFe-layered double hydroxide (CoFe-LDH) could be grown on carbon felt, which was then used in the electro-Fenton system. The catalyst could increase the system reaction rate to produce ferrous ions and hydroxyl radicals that would effectively degrade organic pollutants [6]. Carbon nanotube (CNT) structures are formed from carbon atoms in $\mathrm{sp}^{2}$-mixed orbitals with carbon-to-carbon double bonds. CNTs are multifunctional and porous, with high conductivity and specific surface area. Moreover, they can assist in electron transfer. Wang et al. indicated that the adsorption capacity of multi-wall carbon nanotubes (MWCNTs) was higher than that of activated carbon (AC) and that the surfaces of CNTs promoted the adsorption of hydrocarbons; therefore, they were suitable for treating contaminants [7]. Graphene has a hexagonal honeycomb lattice arrangement (single-layer 2D crystal film) formed from carbon atoms in the $\mathrm{sp}^{2}$ orbital. Graphene can be thought of as having a single layer, 2D, carbon-atom-thick structure formed from carbon atoms and covalent bonds [8]. Graphene has excellent electrochemical characteristics, such as fast electron transfer rates and good conductivity; it exhibits a great potential for use as an electrode material. Tsai et al. used CNT/graphene-modified carbon cloth in microbial fuel cells to effectively increase the power density and reduce the internal resistance [9]. Le et al. reported that their coatings were made of reduced graphene oxide (rGO) on carbon felt. Their results indicated that the charge-transfer resistance for the electrode decreased and the cyclic voltammetry $(\mathrm{CV})$ response increased by $\sim 2.5$ times [10].

In recent years, carbon materials with 3D structures have been studied; they can be used in electrochemistry as sensors [11]. To change the morphology of the materials, many researchers have used different processing methods. Furthermore, CNTs and graphene have been used to synthesize composition materials and they have been applied in various fields [12-14]. Khoshnevis et al. used floating-catalyst chemical vapor deposition (FC-CVD) to produce CNT fibers and the results showed that for different winding rates, the CNT fibers displayed changes in porosity and density, which further affected the mechanical properties [15]. Ioniță et al. synthesized cellulose acetate (CA) membranes doped with CNTs and graphene oxide (GO) and the membranes exhibited outstanding biological performance [16]. Mousset et al. used graphene with 2D structures and graphene foam with 3D structures as electrodes to treat phenol in the electro-Fenton system. The results showed that for the graphene foam with a porous structure and high specific surface area, the phenol degradation was 2.5 times higher than that of the graphene with a 2D structure [17]. In summary, the combination of CNTs and graphene can change the morphology of the electrode material they are deposited on and influence the properties of the electrode.

According to the literature cited above, CNTs and graphene have been widely used as electrode materials; however, hardly any research has demonstrated the difference between the efficiency of CNTs and graphene material in the electro-Fenton system. In this study, carbon felt was used as the substrate and CNTs and graphene were used to modify the electrodes; this was expected to increase the specific surface area and the property for oxidation-reduction reactions of the cathode in the electro-Fenton system. The effects of the modified carbon felt material on the cathode plates were investigated. 


\section{Materials and Methods}

\subsection{Experimental Procedure}

A $250 \mathrm{~mL}$ beaker was used as the experiment tank along with an electrochemical workstation with three electrodes. A Pt plate served as the anode. The working electrodes were unmodified, CNT-modified, and graphene-modified carbon felts. $\mathrm{Ag} / \mathrm{AgCl}$ was the reference electrode. The distance between the working electrode and the counter electrode was $15 \mathrm{~mm}$. The solution in the reaction tank contained $0.1 \mathrm{M}$ potassium nitrate $\left(\mathrm{KNO}_{3}\right)$ and $20 \mathrm{ppm}$ ferrous sulfate $\left(\mathrm{FeSO}_{4} \cdot 7 \mathrm{H}_{2} \mathrm{O}\right)$. The $\mathrm{O}_{2}$ flow rate was $50 \mathrm{sccm}$. Nitric acid was used to maintain the $\mathrm{pH}$ at 3. An air pump was used to introduce oxygen while the solution was magnetically stirred for homogeneity. The optimal potential was $-0.65 \mathrm{~V}$ for each electrode in this study $[17,18]$. When measuring the $\mathrm{H}_{2} \mathrm{O}_{2}$ yields for each electrode, the solution only contained $0.1 \mathrm{M} \mathrm{KNO}_{3}$ in the tank; titanium(IV) sulfate $\left(\mathrm{Ti}\left(\mathrm{SO}_{4}\right)_{2}\right)$ was used as the reagent that reacted with the $\mathrm{H}_{2} \mathrm{O}_{2}$ produced during the electrogeneration process. The absorbance for the sample mixed with $\mathrm{Ti}\left(\mathrm{SO}_{4}\right)_{2}$ and $\mathrm{H}_{2} \mathrm{O}_{2}$ was measured using a visible-light spectrophotometer (wavelength: $410 \mathrm{~nm}$ ) and the calibration curve was used to determine the concentration of $\mathrm{H}_{2} \mathrm{O}_{2}$ [19]. The Reactive Black 5 (RB 5) azo dye was employed to evaluate the decolorization rate of each electrode using the visible-light spectrophotometer. A wavelength of $595 \mathrm{~nm}$ was used to measure the changes in the decolorization level for $30 \mathrm{~min}$ [20]. The experimental setup is shown in Figure 1.

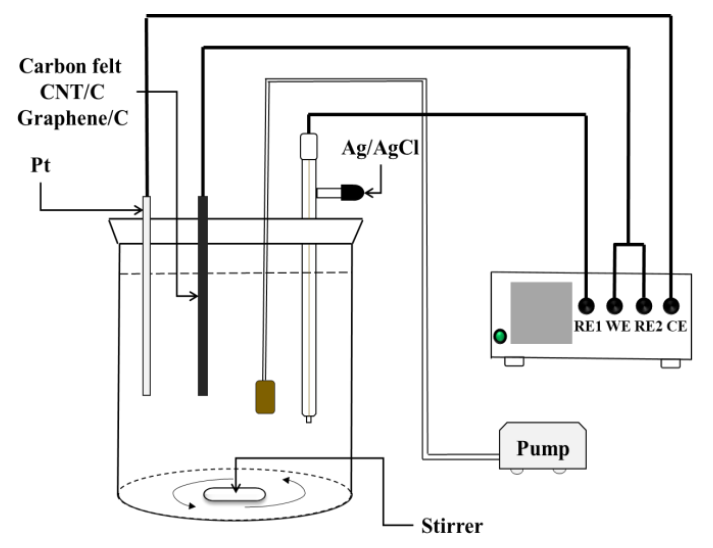

Figure 1. Schematic illustration of the electro-Fenton system.

\subsection{Carbon Felt Electrode Modification}

A carbon felt electrode (length $\times$ width $\times$ height: $20 \times 40 \times 7$; units: $\mathrm{mm}$ ) was used in this study. It was soaked in a $\mathrm{H}_{2} \mathrm{O}_{2}$ and deionized water solution and heated at $90{ }^{\circ} \mathrm{C}$ for $3 \mathrm{~h}$ to increase the hydrophilicity of the carbon felt. To fabricate a CNT-modified carbon felt electrode, CNT and polyvinylidene difluoride (PVDF) powders were mixed in a 3:20 proportion [21]. On the other hand, to fabricate a graphene-modified carbon felt electrode, $0.1 \mathrm{~g}$ of graphene powder was mixed with $2.5 \mathrm{mg}$ of the PVDF powder [22]. After mixing, $50 \mathrm{~mL}$ of N-methyl-2-pyrrolidone (NMP) was added and ultrasound agitation was conducted for $1 \mathrm{~h}$ to achieve slurries. The slurries were dropped onto the carbon felt using the spin-coating method. Finally, both the electrodes were dried in a vacuum oven at $200{ }^{\circ} \mathrm{C}$. Modified working electrodes were obtained after the NMP solution was evaporated.

\section{Results and Discussion}

\subsection{Observation of Electrode Surface}

Figure 2A shows the scanning electron microscopy (SEM) image of the unmodified carbon felt. The image indicates that the fiber surface of the carbon felt is smooth with nothing adhered to it. Figure 2B shows the SEM image of the CNT-PVDF-mixture-modified carbon felt magnified 7000 times. Attached objects are clearly visible on the fiber surface; they allow the CNTs to successfully adhere to the originally 
smooth fiber surface. This increases the specific surface area of the carbon felt. Figure $2 \mathrm{C}$ shows the SEM image of the G-PVDF-mixture-modified carbon felt magnified 7000 times. Scale-like graphene is clearly visible. This shows that thorough mixing with PVDF causes CNTs and graphene to effectively adhere onto the surface of the carbon felt fiber after $2 \mathrm{~h}$ of carbonization at $200{ }^{\circ} \mathrm{C}$. This completes the modification of carbon fibers using high-conductivity graphene in order to increase the specific surface area of the carbon felt. In addition, this improves the conductivity and enhances the system efficiency.

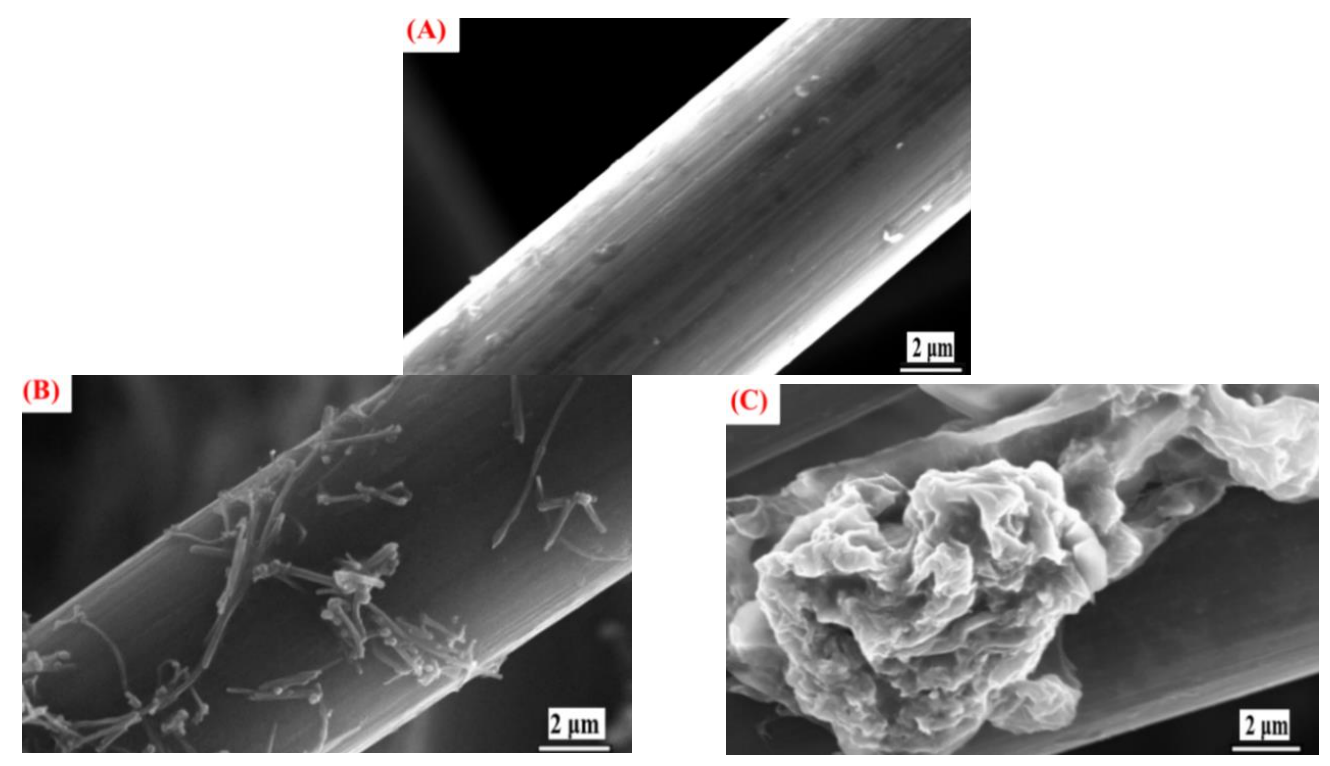

Figure 2. SEM images of carbon felt: (A) Unmodified carbon felt magnified 7000 times, (B) carbon nanotube $(\mathrm{CNT}) / \mathrm{C}$ magnified 7000 times, and (C) graphene/C magnified 7000 times.

\subsection{Fourier-Transform Infrared Spectroscopy Analysis}

Figure 3 shows the Fourier-transform infrared spectroscopy (FTIR) spectra for the different modifications of the carbon felt. The carbon felt and CNTs were not modified in this study; consequently, there are no significant peaks in Figure 3, which indicates that the carbon felt and CNTs have very few oxygen functional groups. Yuan et al. used tin oxide $\left(\mathrm{SnO}_{2}\right)$ and polypyrrole (PPy) nanotubes to modify CNTs. Before the modification, there were no obvious indicative CNT peaks in the FTIR spectra [23]; this is consistent with the results of this study. Unlike the carbon felt and CNT/C electrodes, the graphene/C electrode presents peaks with weak vibration intensities at 3446, 1620, 1212, and $1065 \mathrm{~cm}^{-1}$, which are indicative of $\mathrm{O}-\mathrm{H}, \mathrm{C}=\mathrm{C}, \mathrm{C}-\mathrm{O}-\mathrm{C}$, and C-O bonds, respectively. Graphene only presents a short peak indicative of oxygen functional groups; therefore, we expect it to be hydrophobic for the electrode [24].

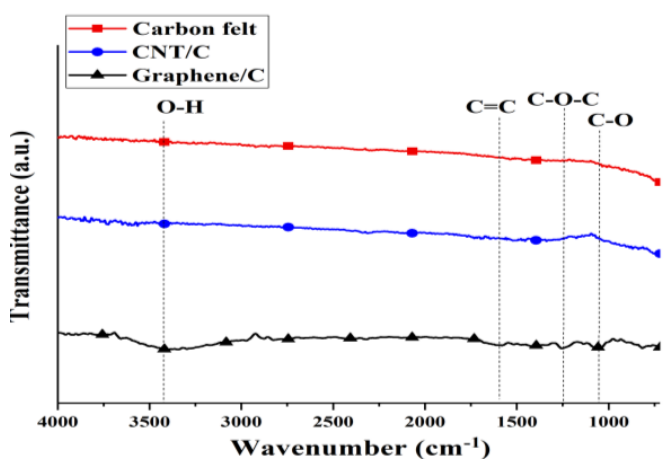

Figure 3. FTIR spectra for different modifications of carbon felt. 


\subsection{Contact Angle Measurement and Analysis}

To further analyze the increase in the specific surface area and performance of the modified carbon felt substrate and the carbon felt electrode, we conducted a water-drop contact angle experiment to measure the hydrophilic characteristics. A smaller contact angle signifies better hydrophilic characteristics of the material toward the solution. The water-drop contact angles of the unmodified, graphene-modified, and CNT-modified carbon felt electrodes were determined to be $144.5^{\circ}, 136.1^{\circ}$, and $78.1^{\circ}$, respectively. The CNT- and graphene-modified electrodes were superior to the untreated carbon felt electrodes. Wang et al. indicated that CNTs exhibited high adsorption capacities [7]. Dhand et al. added CNTs to a PVDF membrane and the contact angle decreased from $103.6^{\circ}$ to $88^{\circ}$ [25]. On the other hand, Wu et al. pointed out that graphene, as well as the membrane prepared by mixing graphene and PVDF, exhibited hydrophobic properties. The contact angle increased with the concentration of graphene [26]; hence, the contact angle for graphene is less than that for CNTs. Incidentally, Miao et al. used sulfonated graphene oxide (SGO) to modify a PVDF substrate. During the measurements, at $600 \mathrm{~s}$, the contact angle (hydrophilic property) changed from $76.8^{\circ}$ to $46.6^{\circ}$ due to the SGO, which had oxygen-containing groups on its edge. This effectively changed the thin film's contact angle, making it more hydrophilic [27].

\subsection{Analysis of $\mathrm{H}_{2} \mathrm{O}_{2}$ Generation}

Linear sweep voltammetry (LSV) results are related to the electric potential change rate and are generally used for studying solid electrodes. The main objective is to determine the scope of the electrochemical reaction. Many reactions involve electron transfer simultaneously accompanied by chemical reactions; consequently, an appropriate electric potential range must be set for scanning, using obtained sufficient information that is beneficial for projecting and analyzing the reaction mechanism. The electric potential scanning rate represents the electrochemical reaction time. Hence, different scanning rates can be used to observe the current and electric potential changes, in order to understand the complex reaction mechanism. For the given cathode, the current responses were driven by oxygen reduction reactions and the 2-electron reaction pathway that generated $\mathrm{H}_{2} \mathrm{O}_{2}$, which are given in Equation (4) and Equation (5), respectively. Therefore, a relatively high net current implies high oxygen reduction reaction activities, which will, in turn, further promote the $\mathrm{H}_{2} \mathrm{O}_{2}$ generation [17]. The optimal potential was in the range of -0.6 to $-0.7 \mathrm{~V}$ for the carbonaceous electrodes; this has also been reported previously $[17,18]$. To measure the response current for each electrode, a fixed scanning rate of $1 \times 10^{-2} \mathrm{~V} / \mathrm{s}$ and scanning voltages from 0 to $-1 \mathrm{~V}$ were used in this experiment. Figure $4 \mathrm{~A}$ displays the response current for each electrode. These results indicated that the cathode modified with graphene showed the highest response current $\left(-4.31 \mathrm{~mA} / \mathrm{cm}^{2}\right)$ at $-0.65 \mathrm{~V}$ due to the enhancement in the conductivity and specific surface area and that it was superior to the CNT-modified $\left(-1.32 \mathrm{~mA} / \mathrm{cm}^{2}\right)$ and unmodified carbon felt electrodes $\left(-0.56 \mathrm{~mA} / \mathrm{cm}^{2}\right)$. To confirm that the results of the LSV experiment were accurate, the $\mathrm{H}_{2} \mathrm{O}_{2}$ concentration was measured using the colorimetry method. Figure $4 \mathrm{~B}$ shows the $\mathrm{H}_{2} \mathrm{O}_{2}$ concentration for different modifications of carbon felt via electrogeneration after $30 \mathrm{~min}$; the graphene/C electrode generated the highest $\mathrm{H}_{2} \mathrm{O}_{2}$ concentration $(0.261 \mathrm{mM})$, which was similar to that generated by the graphene foam electrode with 3D structures prepared by Mousset et al. [17]; the unmodified carbon felt and CNT/C electrodes produced about 0.098 and $0.138 \mathrm{mM}$ of $\mathrm{H}_{2} \mathrm{O}_{2}$ after $30 \mathrm{~min}$, respectively. This implied that the graphene-modified carbon felt plate could stably produce $\mathrm{H}_{2} \mathrm{O}_{2}$ and improve the overall system reaction. In summary, the carbon felt modified with graphene expectedly produced the most $\mathrm{H}_{2} \mathrm{O}_{2}$ and exhibited the best efficiency for RB 5 azo dye treatment.

$$
\begin{array}{cc}
\text { Anode } & 2 \mathrm{H}_{2} \mathrm{O} \rightarrow \mathrm{O}_{2}+4 \mathrm{H}^{+}+4 \mathrm{e}^{-} \\
\text {Cathode } & 2 \mathrm{H}^{+}+2 \mathrm{e}^{-}+\mathrm{O}_{2} \rightarrow \mathrm{H}_{2} \mathrm{O}_{2} .
\end{array}
$$



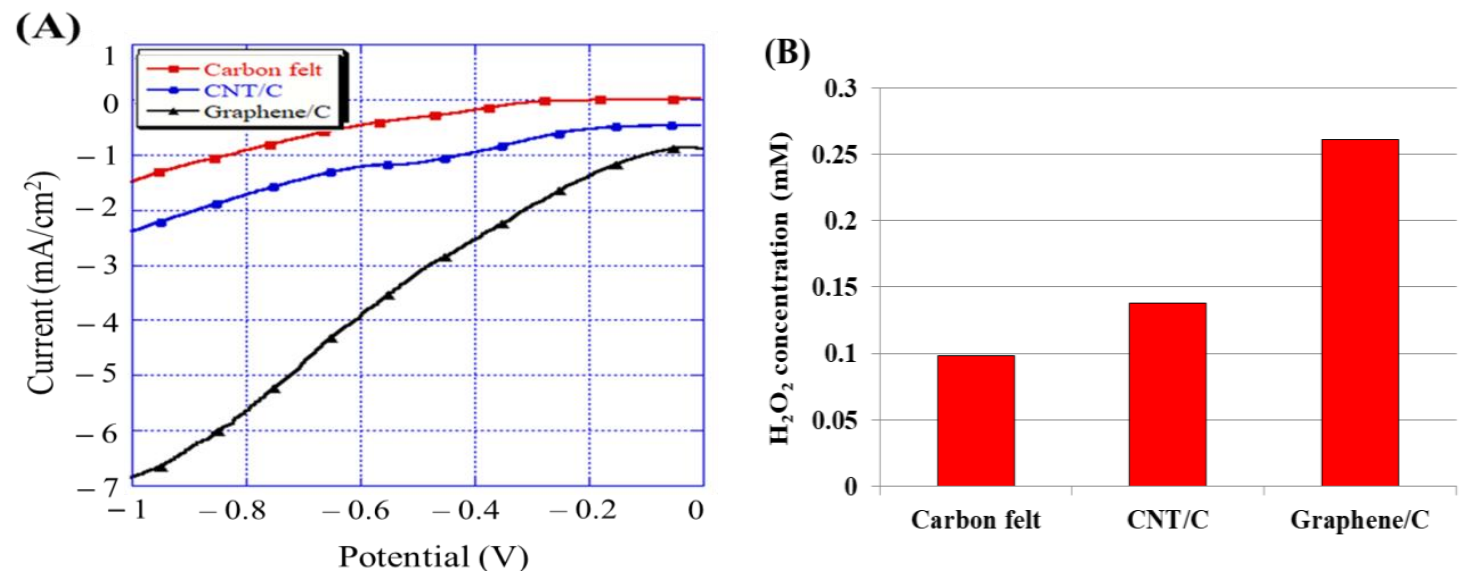

Figure 4. (A) Linear sweep voltammetry curves for different modifications of carbon felt; (B) $\mathrm{H}_{2} \mathrm{O}_{2}$ concentration for different modifications of carbon felt via electrogeneration after $30 \mathrm{~min}(-0.65 \mathrm{~V})$.

\subsection{Tafel Curve Analysis}

The Tafel curve analysis results indicate that a higher corrosion voltage corresponds to a lower electrode activity, which demonstrates that the electrode has a better corrosion resistance, i.e., it is less easily corroded. A smaller corrosion electric potential indicates a higher activity and probability of corrosion. The corrosion voltage can be obtained at the point where the anode and cathode polarization curves intersect [28]. As shown in Figure 5, the measurement indicates that the corrosion voltage of the graphene-modified carbon felt electrode is $489.582 \mathrm{mV}$. This is superior to the $432.212 \mathrm{mV}$ of the CNT-modified carbon felt electrode and the $416.857 \mathrm{mV}$ of the unmodified carbon felt electrode. For a lower corrosion rate and higher corrosion resistance of the electrode, the corrosion current could be obtained using the Tafel extrapolation. The results indicated that the corrosion currents of the CNT- and graphene-modified carbon felt electrodes were $1.07 \times 10^{-7}$ and $2.95 \times 10^{-6} \mathrm{~A}$, respectively. Owing to the outstanding conductivity of graphene, a path for electrochemical reactions was provided; consequently, the corrosion current of the graphene-modified carbon felt electrode was higher than that of the CNT-modified carbon felt electrode [29]. However, the currents of both the modified electrodes were higher than the $5.75 \times 10^{-6}$ A current of the unmodified carbon felt electrode. Therefore, the graphene-modified carbon felt electrode exhibited excellent anticorrosion properties in the electro-Fenton field and prevented the corrosion of the electrode.

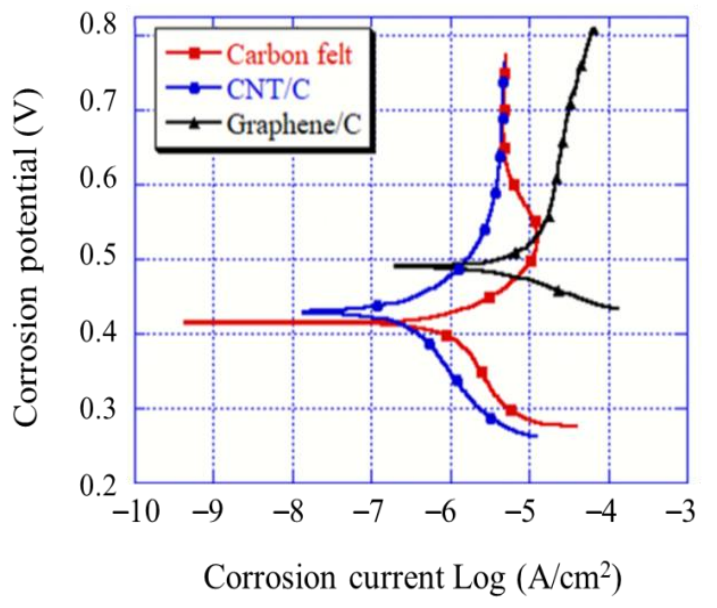

Figure 5. Tafel curves for different modifications of carbon felt. 


\subsection{Cyclic Voltammetry Analysis}

Cyclic voltammetry is used to determine the electrochemical activities of a system. More significant peak values in the test measurements indicate stronger redox activities of the electrodes. This experiment was performed via the impregnation of a $0.01 \mathrm{M}$ potassium ferricyanide $\left(\mathrm{K}_{3}\left[\mathrm{Fe}(\mathrm{CN})_{6}\right]\right)$ solution and the scan rate was set to $10 \mathrm{mV} / \mathrm{s}$. Figure 6 shows the measurement graph and the order is as follows: Peak current $\left(\mathrm{I}_{\mathrm{p}}\right.$; expressed in A) of carbon felt $(6.71 \mathrm{~mA})<\mathrm{CNT}(16.88 \mathrm{~mA})<$ graphene $(60.82 \mathrm{~mA})$. Huang et al. coated graphite felt (GF), polypyrrole/ $\mathrm{ClO}_{4}{ }^{-}$, and polypyrrole/lignin on graphite felt and found that the electroactive surface areas were $4.4,43.1$, and $60.8 \mathrm{~cm}^{2}$, respectively [30]. Therefore, the experimental results could be used in the Randles-Sevcik equation given in Equation (6) [17,31] to assign the peak current $\left(\mathrm{I}_{\mathrm{p}}\right)$ to the electroactive surface area (A) of the electrode, where $n$ is the number of electrons participating in the redox reaction $(n=1), \mathrm{D}$ is the coefficient of the probe molecule $\left(7.60 \times 10^{-6} \mathrm{~cm}^{2} / \mathrm{s}\right), C$ is the concentration of the probe molecule $\left(1 \times 10^{-5} \mathrm{~mol} / \mathrm{cm}^{3}\right)$, and $\gamma$ is the scan rate of the potential perturbation $(0.01 \mathrm{~V} / \mathrm{s})$. The order of the display electrode surface areas was as follows: Carbon felt $\left(9.03 \mathrm{~cm}^{2}\right)<\mathrm{CNT} / \mathrm{C}\left(22.76 \mathrm{~cm}^{2}\right)<$ Graphene/C $\left(82.02 \mathrm{~cm}^{2}\right)$. The high electroactive surface area could be attributed to the enhancement in the specific surface area; this is consistent with the results of Mousset et al. [17]. Moreover, the high electroactive surface area could be used to predict an increase in the degradation rate in the electro-Fenton system.

$$
\mathrm{I}_{\mathrm{p}}=2.69 \times 10^{5} \times \mathrm{AD}^{1 / 2} \mathrm{n}^{1 / 2} \gamma^{1 / 2} \mathrm{C} .
$$

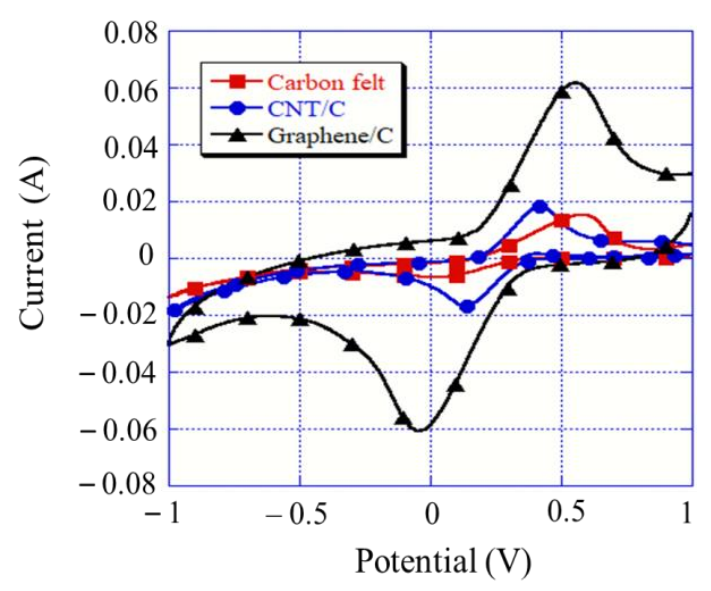

Figure 6. Cyclic voltammetry curves for different modifications of graphite felt.

\subsection{RB 5 Degradation Level Analysis}

In this study, 40 ppm of the RB 5 azo dye was used to evaluate the treatment efficiency in the electro-Fenton system. The experiment was conducted for $30 \mathrm{~min}$. The light absorbance was measured at intervals of $3 \mathrm{~min}$. The unmodified, CNT-modified, and graphene-modified carbon felt electrodes were all analyzed, as shown in Figure 7. The graphene- and CNT-modified carbon felt electrodes were superior to the unmodified carbon felt electrode in terms of RB 5 decolorization in the electro-Fenton system $\left(70.12 \%\right.$ and $55.34 \%$, respectively). During the LSV and $\mathrm{H}_{2} \mathrm{O}_{2}$ concentration measurements, a high response current indicated a high $\mathrm{H}_{2} \mathrm{O}_{2}$ production and hydroxyl radical generation, which led to further attack on the $-\mathrm{N}=\mathrm{N}$ - double bond in the dye. Nam et al. used a Fenton system with ethylenediaminetetraacetic acid (EDTA) to decolorize an azo dye and effectively treat wastewater. The reaction time for decolorizing methyl red was $10 \mathrm{~min}$ (decolorization rate of $71 \%$ ). For Orange I, the reaction time was 2 min (decolorization rate of 98\%). This indicated that the Fenton system underwent a superior reaction. They also proposed that excess $\mathrm{H}_{2} \mathrm{O}_{2}$ would not produce good results in the Fenton reaction [32]. 


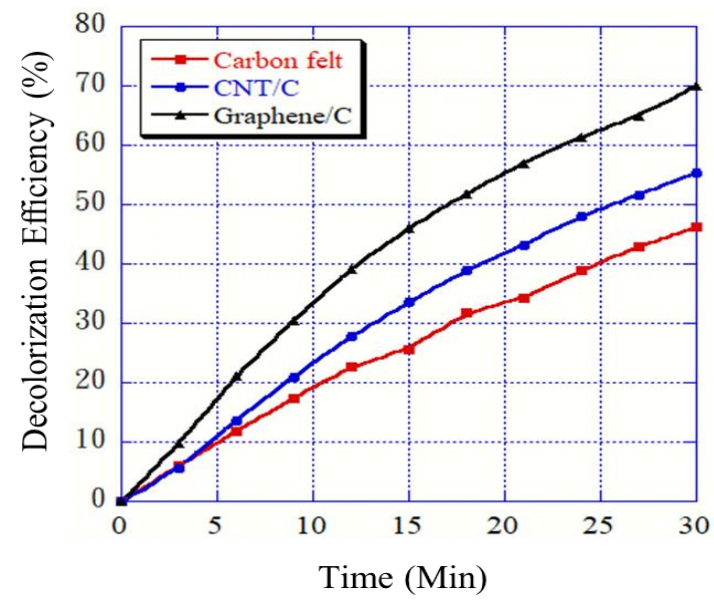

Figure 7. Plots of decolorization rates for different modifications of carbon felt in electro-Fenton system.

The total organic carbon (TOC) was determined using the ultraviolet light-persulfate photochemical oxidation method to analyze the organic matter content in the sewage. The TOC calculation method was based on Equation (7), where $\triangle \mathrm{TOC}$ is the change in the concentration response and $\mathrm{TOC}_{0}(\mathrm{mg} / \mathrm{L})$ is the initial value of total organic carbon. For the graphite felt $(\mathrm{GF})$, the taffeta carbon fiber (TCF) removal of pyrimethanil indicated a TOC removal at $0.3 \mathrm{~A}$ of up to $42.36 \%$ after $120 \mathrm{~min}$ of the electro-Fenton reaction [33]. Zhou et al. used CF to decompose $p$-nitrophenol contaminants in the electro-Fenton system, with a TOC removal rate of $22.2 \%$ in $30 \mathrm{~min}$ and a CF treated with ethanol and hydrazine hydrate $\left(\mathrm{N}_{2} \mathrm{H}_{4} \cdot \mathrm{H}_{2} \mathrm{O}\right)$ TOC removal rate of $51.4 \%$ [34]. This implied that the treated carbon felt in the electro-Fenton system could effectively reduce the organic pollutants in the sewage. Therefore, an experiment on the degradation of organic pollutants in the electro-Fenton process was performed using graphene-modified, CNT-modified, and unmodified carbon felt electrodes. The respective TOC removal rates were $55.56 \%, 50.13 \%$, and $10.60 \%$ after $30 \mathrm{~min}$. Due to the complexity of the RB 5 molecule, the TOC removal rate was lower than the decolorization rate in the electro-Fenton system [35], as shown in Table 1. The results obtained for the modified carbon felts were more than five times higher than those for the unmodified carbon felt. The modified electrodes could effectively increase the system reaction rate and degrade the organic pollutants, thereby purifying the wastewater. According to the LSV and CV analyses, the high response current and electroactive surface area improved the degradation rate in the electro-Fenton system. These results indicated that the graphene-modified electrode could produce high quantities of $\mathrm{H}_{2} \mathrm{O}_{2}$, which is consistent with the TOC analysis results. The system produced large quantities of hydroxyl radicals and broke down the azo dye, thereby achieving wastewater purification.

$$
\text { TOC removal }(\%)=\left(\triangle \mathrm{TOC} / \mathrm{TOC}_{0}\right) \times 100 .
$$

Table 1. Decolorization efficiency and total organic carbon (TOC) removal after $30 \mathrm{~min}$ of the electro-Fenton treatment proposed in this work (40 ppm Reactive Black 5 (RB 5)).

\begin{tabular}{cccc}
\hline Cathode & Carbon Felt & CNT/C & Graphene/C \\
\hline Response Current $(-0.65 \mathrm{~V})$ & $-0.56 \mathrm{~mA} / \mathrm{cm}^{2}$ & $-1.32 \mathrm{~mA} / \mathrm{cm}^{2}$ & $-4.31 \mathrm{~mA} / \mathrm{cm}^{2}$ \\
$\mathrm{H}_{2} \mathrm{O}_{2}$ yield & $0.098 \mathrm{mM}$ & $0.138 \mathrm{mM}$ & $0.261 \mathrm{mM}$ \\
Electroactive surface area & $9.03 \mathrm{~cm}^{2}$ & $22.76 \mathrm{~cm}^{2}$ & $82.02 \mathrm{~cm}^{2}$ \\
Decolorization efficiency & $46.15 \%$ & $55.34 \%$ & $70.12 \%$ \\
TOC removal & $10.60 \%$ & $50.13 \%$ & $55.56 \%$ \\
\hline
\end{tabular}




\section{Conclusions}

In this study, carbon felt electrodes were modified with CNTs and graphene and their characteristics as electro-Fenton system cathodes were investigated by processing RB 5 wastewater.

The following conclusions were drawn.

1. The surface morphology showed that the CNT and graphene modifications of the carbon felt electrodes led to the roughening of the smooth carbon felt fiber surface. This assisted in improving the specific surface area and conductivity of the carbon felt. The contact angles indicated that the CNT- and graphene-modified carbon felt electrodes exhibited higher hydrophilicity. This effectively improved the tank electrode and solution reaction time in the electro-Fenton system.

2. The graphene-modified carbon felt exhibited the best reaction rate and electrochemical activity, based on the LSV and CV tests. A high current indicated the enhancement in the response of the electro-Fenton system. The Tafel curve showed that the corrosion resistance of the electrode was also improved by the modification; the modified carbon felt electrodes exhibited superior corrosion resistance compared to the conventional carbon felt plate.

3. When a working electrode was applied to degrade the RB 5 azo dye in the electro-Fenton system, the decolorization rate of the CNT-modified carbon felt electrode was $55.3 \%$ and that of the graphene-modified carbon felt electrode was $70.1 \%$, which were, respectively, 1.2 and 1.5 times higher than that of the unmodified carbon felt electrode. A TOC-removal experiment proved that the modified electrode could effectively degrade organic pollutants and improve the system efficiency.

The results indicate that graphene-modified electrodes can produce a high quantity of $\mathrm{H}_{2} \mathrm{O}_{2}$, which is consistent with the TOC analysis results. The system produced large quantities of hydroxyl radicals and broke down the azo dye, thereby achieving wastewater purification. Assuming that the additive quantities were equal, the graphene-modified carbon felt was superior to CNT-modified carbon felt. Both the modified felts exhibited effectively increased conductivity and corrosion resistance and both improved the degrading efficiency of the cathode.

Author Contributions: Y.-T.W. conceived the study, designed the experiments, analyzed the data, and wrote the paper; C.-H.T. and Y.-S.L. performed the experiments.

Funding: The financial support provided by the National Science Council of the Republic of China (Taiwan) through the MOST 107-2221-E-197-023 projects is greatly appreciated.

Conflicts of Interest: The authors declare no conflict of interest.

\section{References}

1. Brillas, E.; Sirés, I.; Oturan, M.A. Electro-Fenton process and related electrochemical technologies based on Fenton's reaction chemistry. Chem. Rev. 2009, 109. [CrossRef] [PubMed]

2. Khoufi, S.; Aloui, F.; Sayadi, S. Treatment of olive oil mill wastewater by combined process electro-Fenton reaction and anaerobic digestion. Water Res. 2006, 40, 2007-2016. [CrossRef] [PubMed]

3. Özcan, A.; Şahin, Y.; Koparal, A.S.; Oturan, M.A. A comparative study on the efficiency of electro-Fenton process in the removal of propham from water. Appl. Catal. B 2009, 89, 620-626. [CrossRef]

4. Huggins, T.; Wang, H.; Kearns, J.; Jenkins, P.; Ren, Z.J. Biochar as a sustainable electrode material for electricity production in microbial fuel cells. Bioresour. Technol. 2014, 157, 114-119. [CrossRef]

5. Le, T.X.H.; Bechelany, M.; Cretin, M. Carbon felt based-electrodes for energy and environmental applications: A review. Carbon 2017, 122, 564-591.

6. Ganiyu, S.O.; Le, T.X.H.; Bechelany, M.; Esposito, G.; van Hullebusch, E.D.; Oturan, M.A.; Cretin, M. A hierarchical CoFe-layered double hydroxide modified carbon-felt cathode for heterogeneous electro-Fenton process. J. Mater. Chem. A 2017, 5, 3655-3666. [CrossRef]

7. Wang, Y.; Pan, C.; Chu, W.; Vipin, A.K.; Sun, L. Environmental remediation applications of carbon nanotubes and graphene oxide: Adsorption and catalysis. Nanomaterials 2019, 9, 439. [CrossRef] [PubMed] 
8. Novoselov, K.S.; Blake, P.; Katsnelson, M.I. Graphene: Electronic properties. In Encyclopedia of Materials: Science and Technology; Elsevier: Amsterdam, The Netherlands, 2008; pp. 1-6.

9. Tsai, H.Y.; Hsu, W.H.; Huang, Y.C. Characterization of carbon nanotube/graphene on carbon cloth as an electrode for air-cathode microbial fuel cells. J. Nanomater. 2015, 3, 2015. [CrossRef]

10. Le, T.X.H.; Bechelany, M.; Champavert, J.; Cretin, M. A highly active based graphene cathode for the electro-Fenton reaction. RSC Adv. 2015, 5, 42536-42539. [CrossRef]

11. Liu, Y.; Wang, Y. Size-dependent free vibration and buckling of three-dimensional graphene foam microshells based on modified couple stress theory. Materials 2019, 12, 729. [CrossRef] [PubMed]

12. Duong, H.M.; Tran, T.Q.; Kopp, R.; Myint, S.M.; Peng, L. Direct spinning of horizontally aligned carbon nanotube fibers and films from the floating catalyst method. In Nanotube Super Fiber Materials, 2nd ed.; William Andrew Publishing: Oxford, UK, 2019; pp. 3-29.

13. Iijima, S. Carbon nanotubes: Past, present, and future. Phys. B (Amsterdam, The Netherlands) 2002, 323, 1-5. [CrossRef]

14. Muhulet, A.; Miculescu, F.; Voicu, S.I.; Schütt, F.; Thakur, V.K.; Mishra, Y.K. Fundamentals and scopes of doped carbon nanotubes towards energy and biosensing applications. Mater. Today Energy 2018, 9, 154-186. [CrossRef]

15. Khoshnevis, H.; Tran, T.Q.; Mint, S.M.; Zadhoush, A.; Duong, H.M.; Youssefi, M. Effect of alignment and packing density on the stress relaxation process of carbon nanotube fibers spun from floating catalyst chemical vapor deposition method. Colloids Surf. A: Physicochem. Eng. Asp. 2018, 558, 570-578. [CrossRef]

16. Ioniță, M.; Crică, L.E.; Voicu, S.I.; Dinescu, S.; Miculescu, F.; Costache, M.; Lovu, H. Synergistic effect of carbon nanotubes and graphene for high performance cellulose acetate membranes in biomedical applications. Carbohydr. Polym. 2018, 183, 50-61.

17. Mousset, E.; Wang, Z.; Hammaker, J.; Lefebvre, O. Physico-chemical properties of pristine graphene and its performance as electrode material for electro-Fenton treatment of wastewater. Electrochim. Acta 2016, 214, 217-230. [CrossRef]

18. Wang, Y.; Liu, Y.; Wang, K.; Song, S.; Tsiakaras, P.; Liu, H. Preparation and characterization of a novel KOH activated graphite felt cathode for the electro-Fenton process. Appl. Catal. B 2015, 165, 360-368. [CrossRef]

19. Babaei-Sati, R.; Basiri Parsa, J. Electrogeneration of $\mathrm{H}_{2} \mathrm{O}_{2}$ using graphite cathode modified with electrochemically synthesized polypyrrole/MWCNT nanocomposite for electro-Fenton process. J. Ind. Eng. Chem. 2017, 52, 270-276. [CrossRef]

20. Sahel, K.; Perol, N.; Chermette, H.; Bordes, C.; Derriche, Z.; Guillard, C. Photocatalytic decolorization of Remazol Black 5 (RB5) and Procion Red MX-5B-Isotherm of adsorption, kinetic of decolorization, and mineralization. Appl. Catal. B. 2007, 77, 100-109. [CrossRef]

21. Mishra, S.; Kumaran, K.T.; Sivakumaran, R.; Pandian, S.P.; Kundu, S. Synthesis of PVDF/CNT and their functionalized composites for studying their electrical properties to analyze their applicability in actuation \& sensing. Colloids Surf. A: Physicochem. Eng. Asp. 2016, 509, 684-696.

22. Ataur Rahman, M.; Chung, G.S. Synthesis of PVDF-graphene nanocomposites and their properties. J. Alloys Compd. 2013, 581, 724-730. [CrossRef]

23. Yuan, J.; Hao, Y.; Zhang, X.; Li, X. Sandwiched $\mathrm{CNT} @ S n O_{2} @ P P y$ nanocomposites enhancing sodium storage. Colloids Surf. A: Physicochem. Eng. Asp. 2018, 555, 795-801. [CrossRef]

24. Ren, W.; Chang, H.; Mao, T.; Teng, Y. Planarity effect of polychlorinated biphenyls adsorption by graphene nanomaterials: The influence of graphene characteristics, solution $\mathrm{pH}$, and temperature. Chem. Eng. J. 2019, 362, 160-168. [CrossRef]

25. Dhand, V.; Hong, S.K.; Li, L.; Kim, J.M.; Kim, S.H.; Rhee, K.Y.; Lee, H.W. Fabrication of robust, ultrathin, and light weight, hydrophilic, PVDF-CNT membrane composite for salt rejection. Compos. B: Eng. 2019, 160, 632-643. [CrossRef]

26. Wu, X.; Zhao, B.; Wang, L.; Zhang, Z.; Zhang, H.; Zhao, X.; Guo, X. Hydrophobic PVDF/graphene hybrid membrane for $\mathrm{CO}_{2}$ absorption in membrane contactor. J. Membr. Sci. 2016, 520, 120-129. [CrossRef]

27. Miao, W.; Li, Z.K.; Yan, X.; Guo, Y.J.; Lang, W.Z. Improved ultrafiltration performance and chlorine resistance of PVDF hollow fiber membranes via doping with sulfonated graphene oxide. Chem. Eng. J. 2017, 317, 901-912. [CrossRef] 
28. Raza, M.A.; Ali, A.; Ghauri, F.A.; Aslam, A.; Yaqoob, K.; Wasay, A.; Raffi, M. Electrochemical behavior of graphene coatings deposited on copper metal by electrophoretic deposition and chemical vapor deposition. Surf. Coat. Technol. 2017, 332, 112-119. [CrossRef]

29. Tamilarasan, T.R.; Sanjith, U.; Siva Shankar, M.; Rajagopal, G. Effect of reduced graphene oxide (rGO) on corrosion and erosion-corrosion behaviour of electroless Ni-P coatings. Wear 2017, 390-391, 385-391. [CrossRef]

30. Huang, H.; Han, C.; Wang, G.; Feng, C. Lignin combined with polypyrrole as a renewable cathode material for $\mathrm{H}_{2} \mathrm{O}_{2}$ generation and its application in the electro-Fenton process for azo dye removal. Electrochim. Acta 2018, 259, 637-646. [CrossRef]

31. Bard, A.J.; Faulkner, L.R. Electrochemical Methods: Fundamentals and Applications; John Wiley \& Sons: New York, NY, USA, 2000.

32. Nam, S.; Renganathan, V.; Tratnyek, P.G. Substituent effects on azo dye oxidation by the FeIII-EDTA- $\mathrm{H}_{2} \mathrm{O}_{2}$ system. Chemosphere 2001, 45, 59-65. [CrossRef]

33. Popescu, M.; Sandu, C.; Rosales, E.; Pazos, M.; Lazar, G.; Sanromán, M.Á. Evaluation of different cathodes and reaction parameters on the enhancement of the electro-Fenton process. J. Electroanal. Chem. 2018, 808, 455-463. [CrossRef]

34. Zhou, L.; Zhou, M.; Hu, Z.; Bi, Z.; Serrano, K.G. Chemically modified graphite felt as an efficient cathode in electro-Fenton for $p$-nitrophenol degradation. Electrochim. Acta 2014, 140, 376-383. [CrossRef]

35. Vasconcelos, V.M.; Ponce-de-León, C.; Nava, J.L.; Lanza, M.R.V. Electrochemical degradation of RB-5 dye by anodic oxidation, electro-Fenton and by combining anodic oxidation-electro-Fenton in a filter-press flow cell. J. Electroanal. Chem. 2016, 765, 179-187. [CrossRef]

(C) 2019 by the authors. Licensee MDPI, Basel, Switzerland. This article is an open access article distributed under the terms and conditions of the Creative Commons Attribution (CC BY) license (http://creativecommons.org/licenses/by/4.0/). 